\title{
Microalbuminuria in HIV infection
}

\author{
Lynda Anne Szczech ${ }^{\mathrm{a}}$, Carl Grunfeld ${ }^{\mathrm{b}, \mathrm{c}}$, Rebecca Scherzer ${ }^{\mathrm{c}}$, Jesse A. Canchola ${ }^{\mathrm{c}, \mathrm{d}}$, Charles \\ van der Horst ${ }^{e}$, Stephen Sidney ${ }^{f}$, David Wohl ${ }^{e}$, and Michael G. Shlipak ${ }^{b, c}$ \\ aDuke University Medical Center, Department of Medicine, Division of Nephrology, Durham, \\ North Carolina, USA \\ bUniversity of California, San Francisco, California, USA \\ 'San Francisco Veterans Affairs Medical Center, San Francisco, California, USA \\ dCalifornia State University, East Bay, Department of Statistics, Hayward, California, USA \\ eNorth Carolina, Department of Medicine, Division of Infectious Diseases, Chapel Hill, North \\ Carolina, USA \\ fKaiser Permanente Northern California Division of Research, Oakland, California, USA
}

\section{Abstract}

Objective-Microalbuminuria is associated with increased risk of cardiovascular disease and mortality. The objective of the study was to evaluate if HIV infection was an independent risk factor for microalbuminuria.

Design-Cross sectional.

Methods-The relationship between HIV infection and microalbuminuria was assessed using subjects enrolled in the study of Fat Redistribution and Metabolic Change in HIV Infection, which consists of HIV-positive and control men and women. Participants with proteinuria (dipstick $\geq 1+$ ) were excluded.

Results-Microalbuminuria (urinary albumin/creatinine ratio, ACR $>30 \mathrm{mg} / \mathrm{g}$ ) was present in $11 \%$ of HIV infected, and $2 \%$ of control participants $(P<0.001)$; a fivefold odds after multivariate adjustment (odds ratio, 5.11; 95\% confidence interval, 1.97-13.31; $P=0.0008$ ). Several cardiovascular risk factors were associated with higher ACR in HIV participants: insulin resistance (HOMA $>4 ; 32 \%, P<0.0001)$, systolic blood pressure ( $21 \%, P=0.01$ for $120-140$ versus $<120 \mathrm{mmHg}$, and $43 \%, P<0.06$ for $>140$ versus $<120 \mathrm{mmHg}$ ), and family history of hypertension $(17 \%, P=0.03)$. Higher CD4 cell count was associated with lower albumin/creatinine ratio $(-24 \%$, $P=0.009$ for $200-400$ versus $<200$ cells $/ \mathrm{ml}$ and $-26 \%, P=0.005$ for $>400$ versus $<200$ cells $/ \mathrm{ml}$ ).

Conclusion-HIV infection had a strong and independent association with microalbuminuria, the severity of which was predicted by markers of insulin resistance, hypertension, and advanced HIV infection. These associations warrant further investigation, as the increased prevalence of microalbuminuria in HIV infection may be a harbinger of future risk of cardiovascular and kidney diseases.

\section{(C) 2007 Lippincott Williams \& Wilkins}

Correspondence to C. Grunfeld, University of California, San Francisco, Veterans Affairs Medical Center, Metabolism Section 111F, 4150 Clement Street, San Francisco, CA 94121, USA. Tel: +1 415750 2005; fax: +1 415750 6927; carl.grunfeld@ucsf.edu.

These data were presented at the Twelfth Conference on Retroviruses and Opportunistic Infections. Boston, MA, February 2005 [abstract 821]. 


\section{Keywords}

Microalbuminuria; kidney; urine protein; insulin resistance; lipodystrophy

\section{Introduction}

Renal disease manifesting as proteinuria or elevated creatinine has been described as a common complication of HIV infection. Among a cohort of women with HIV infection, $39 \%$ of African-American and $25 \%$ of Caucasian women had clinically significant proteinuria [1]. These levels of proteinuria have subsequently been demonstrated to be associated with poorer outcomes including an increased risk of hospitalization and mortality [2-4]. Risk factors for clinically significant proteinuria include African-American race, higher HIV RNA level, and lower CD4 lymphocyte count [1].

Similar to the data on prevalence of proteinuria, a strikingly high prevalence of microalbuminuria among HIV-infected patients of 19\%, 30\%, and 34\% has been described in three studies [5-7]. One of these reports suggested that patients with 'clinical AIDS' or 'AIDS related complex' may be at greater risk compared with asymptomatic HIV-infected individuals [7]. Since the publication of these studies (1992, 1993, and 1996), the treatment of HIV infection has changed dramatically. With the introduction of protease inhibitors and highly active antiretroviral therapy, survival of patients with HIV infection has improved substantially [8,9]. However, concurrent with this improved survival, changes in fat distribution, worsening lipid profiles, and insulin resistance have also been noted [10-12]. Recent data indicate that the rate of cardiovascular disease is increased in patients with HIV infection on combination antiretroviral therapy, although the role of antiretroviral therapy and abnormalities of body composition is debated [13,14].

Microalbuminuria is a marker of renal damage that is associated with increased risk of cardiovascular disease and mortality in the general population [15-18]. Given these associations, microalbuminuria may be an important early marker of cardiovascular disease risk in persons with HIV infection [19,20]. We hypothesized that HIV infection would be associated with greater prevalence of microalbuminuria compared with similarly aged controls. Using the Study of Fat Redistribution and Metabolic Change in HIV Infection (FRAM) cohort, comprised of both HIV-infected and control participants, this study was undertaken to compare the prevalence of microalbuminuria in each group and explore predictors of microalbuminuria among persons with HIV infection.

\section{Methods}

\section{Subjects}

Briefly, FRAM is a cross-sectional study with the overall objective to evaluate abnormalities in fat distribution using measurement of regional subcutaneous adipose tissue (SAT) and visceral adipose tissue (VAT) by magnetic resonance imaging in HIV-infected subjects and control subjects, as well as physical examination and laboratory examination of metabolic parameters. HIV-infected subjects were recruited from 16 HIV or infectious disease clinics or cohorts during 1999. FRAM is representative of patients with HIV infection in the U.S. [21]. Control subjects were recruited from two centers of the Coronary Artery Risk Development in Young Adults (CARDIA) study [22]. CARDIA subjects were originally recruited as a population-based sample of healthy 18-30-year-old white and AfricanAmerican men and women from four cities in 1985-1986 for a longitudinal study of cardiovascular risk factors. Participants who agreed to the year 15 CARDIA examination were approached to participate in FRAM. Eighty participants with significant proteinuria 
( $\geq 1$ by dipstick) and those identifying as non-White or non-Black were excluded from this analysis. The protocol was approved by institutional review boards at all sites. The methods have been described in detail previously [21,23].

\section{Measurements}

Albumin and creatinine concentrations were measured in spot urine specimens obtained in $67 \%$ (967/1451) of subjects. Urine albumin excretion was estimated using the albumin to creatinine ratio (ACR) and calculated by dividing the spot urine albumin concentration by the spot urine creatinine concentration [24-27]. Microalbuminuria was analyzed as both a dichotomous variable defined as ACR $>30 \mathrm{mg} / \mathrm{g}$ and a continuous variable. Prior research from the CARDIA cohort has found that the ability of ACR to approximate 24-h urine albumin excretion differs somewhat by sex and race, due to differences in creatinine production. Within HIV-infected subjects, we used ACR adjustment coefficients for women and African-Americans that were derived by Jacobs and colleagues to reduce sex- and racerelated effects on ACR levels [28]. Serum creatinine was measured and creatinine clearance was calculated using the Cockcroft-Gault formula [29]. The homeostatic method of assessment (HOMA) was utilized to assess beta-cell function and insulin resistance using basal (fasting) glucose and insulin concentrations [30]. Simply, HOMA provides a framework to utilize these two parameters to estimate increasing insulin resistance (i.e., a greater insulin level to achieve the same glucose level) and decreased beta-cell function (i.e., a greater glucose level given a degree of insulin sensitivity). Among HIV-infected subjects, blood was drawn for determination of CD4 cell counts and HIV RNA by PCR and measured in a single laboratory (Covance, Indianapolis, IN, USA).

\section{Statistical analyses}

Clinical and demographic variables were summarized for HIV-infected and control subjects separately stratified on the presence or absence of microalbuminuria (ACR>30 mg/g). Continuous and categorical variables were compared between groups based on the presence or absence of microalbuminuria within cohort defined by HIV infection using Student's ttest or Wilcoxon's rank-sum test and Pearson's chi-square or Fisher's exact test as appropriate.

The first objective of our analysis was to evaluate whether HIV infection was independently associated with a greater prevalence of microalbuminuria (ACR $>30 \mathrm{mg} / \mathrm{g}$ ) compared with the control population. Multivariable logistic regression was used with adjustment for other predictors of microalbuminuria that were measured in both HIV-infected and controls. These analyses were repeated using linear regression to evaluate the presence of HIV infection as a predictor of ACR as a continuous variable; because of its skewed distribution, ACR was log-transformed in all linear regression analyses. Variables tested to determine if they confounded the association between ACR and HIV infection include demographics (age, sex, race), medical history (presence of HIV infection, diabetes mellitus, or hypertension; family history of kidney disease or hypertension), physical exam parameters (systolic and diastolic blood pressure), laboratory parameters (the presence of urine glucose, HOMA, social history (self-reported use of illicit drugs), medications (statins, ACE-I, antihypertensives), and assessments of visceral and regional subcutaneous adipose tissue (VAT and SAT) volume.

The second major objective of the analysis was to evaluate the determinants of ACR among the HIV-infected participants. ACR was analyzed as a continuous variable based on its previously described association with mortality [15]; we incorporated ACR adjustment coefficients, derived by Jacobs and colleagues, to minimize sex and race effects on ACR levels [28]. The first of these two models tested all of the variables listed above plus 
including HIV specific parameters [i.e., current HIV RNA level $\left(\log _{10}\right)$, current CD4 lymphocyte count $\left(\log _{2}\right)$, duration of HIV infection, and risk behavior for HIV acquisition]. The second of these two models included all variables listed above, HIV specific parameters, and use or duration of individual antiretroviral medications (e.g., stavudine, zidovudine, etc.) as well as classes of antiretroviral medications [nucleoside/nucleotide reverse transcriptase inhibitors, non-nucleoside reverse transcriptase inhibitors (NNRTI), or protease inhibitors]. Duration or use of each antiretroviral agent, antiretroviral agent class, and HAART as previously defined [22] were added to the model in a forward stepwise manner. These models were fitted to logarithmic transformations of ACR to produce estimated percentage differences in ACR levels. Multivariate regression models were built using stepwise regression, with $P=0.05$ for entry and retention and with gender, age, and ethnicity forced to be included in every model. Confidence intervals were determined using the bias-corrected accelerated bootstrap method [31], with $P$ values defined as the one minus the highest confidence level that still excluded zero. This was necessary both because the outcome appeared to be non-Gaussian, even after log transformation, and to control for multiple important predictors. Model validity was also examined by testing for important interactions, multicollinearity, outliers, etc. (Fig. 1)

\section{Results}

\section{Microalbuminuria among HIV-infected and control participants}

Characteristics of HIV infected participants and controls with and without microalbuminuria are displayed in Table 1. In general, HIV-infected subjects with microalbuminuria (ACR > $30 \mathrm{mg} / \mathrm{g})$ were more likely to be female $(P=0.02)$, African-American $(P=0.0003)$, have an elevated systolic or diastolic pressure or have hypertension $(P=0.0003,0.02$, and 0.002 , respectively), and a lower nadir CD4 lymphocyte count $(P=0.04)$ as compared with HIVinfected subjects without microalbuminuria. Additionally HIV-infected subjects with microalbuminuria had a trend toward more insulin resistance (greater mean HOMA) though this was not statistically significant $(P=0.08)$. Among control subjects, those subjects with microalbuminuria had greater insulin levels, fasting glucose levels, measures of insulin resistance, (i.e., HOMA) $(P=0.04,0.003,0.01)$ and greater triglyceride levels $(P=0.06)$. There were no apparent associations with regional adipose tissue volumes $(P$ values for association with individual adipose tissue depot volumes were all $>0.49$ ).

\section{Association of microalbuminuria with HIV infection}

Microalbuminuria (ACR $>30 \mathrm{mg} / \mathrm{gm}$ ) was present in $83(11 \%)$ of the HIV-infected subjects and $5(2 \%)$ of the controls $(P<0.001)$ (Fig. 1). In the univariate analysis, HIV-infected subjects had a fivefold higher odds than controls of having microalbuminuria $(\mathrm{OR}=4.95, P=$ 0.0002; 95\% CI, 1.98-12.38) (Table 2). After multivariable adjustment for other predictors of micro-albuminuria, the presence of HIV infection remained the strongest predictor of microalbuminuria (OR, 5.11; $P=0.0008$; 95\% CI, 1.97-13.31 for HIV infection) (Table 3). Other predictors of microalbuminuria included African-American race, greater serum triglyceride measurement, greater systolic blood pressure, and female gender. Similarly, when ACR was analyzed as a continuous variable, in the multivariate model of subjects with and without HIV infection, the presence of HIV infection was strongly associated with a higher ACR level (58\%; 95\% CI, 39-82; $P<0.0001)$ compared to control participants.

\section{Predictors of microalbuminuria among HIV-infected participants}

Among participants with HIV infection, older age $(P=0.02)$ and African-American race $(P=0.001)$ were associated with higher ACR. Interactions between ACR and both gender and race were tested in separate models and were not significant $(P>0.05)$. Several traditional cardiovascular risk factors were strongly associated with higher ACR; these 
included insulin resistance (HOMA $>4 ; P<0.0001)$, greater systolic blood pressure $(P=0.01$ for $120-140 \mathrm{mmHg}$ versus $<120 \mathrm{mmHg}$, and $P=0.06$ for $>140 \mathrm{mmHg}$ versus $<120$ $\mathrm{mmHg}$ ), family history of hypertension $(P=0.03)$, and urine glucose $(p=0.002)$. In contrast, tobacco use $(P=0.57)$ was not significantly associated with higher ACR.

HIV-specific risk factors associated with higher ACR were lower CD4 lymphocyte count ( $P=0.009$ for $200-400$ versus $<200$ cells $/ \mathrm{ml}$, and $P=0.005$ for $>400$ versus $<200$ cells $/ \mathrm{ml}$ ), current HIV RNA level $(P=0.05)$, and current use of NNRTI $(P=0.01)$. Current use of NNRTI was the only ARV selected into the model (entrance criterion $P<0.05$ ) among candidate predictors that included duration or use of each individual ARV, class of ARV, and use of HAART regimens. Co-infection with hepatitis $\mathrm{C}$ virus $(P=0.58)$ was not significantly associated with higher ACR.

\section{Discussion}

This analysis demonstrated that HIV infection is a strong risk factor for the presence of microalbuminuria, independent of other risk factors for the presence of renal disease. Among HIV-infected individuals, risk factors for microalbuminuria included traditional HIV specific markers such as CD4 lymphocyte count and HIV RNA level. The association of HIV infection with albuminuria and proteinuria was reported in an earlier era of the HIV epidemic in the USA with a prevalence of between 19 and 34\% [5-7]. One of these prior studies demonstrated associations between the presence of microalbuminuria and 'stage' of HIV-infection [7]. A more recent study also found that HIV RNA level, CD4 lymphocyte count, and African-American race were important determinants of overt proteinuria [1]. In the study described in this report, decreased CD4 cell count, increased viral load, and African-American race were all associated with higher ACR.

However, higher albumin excretion rate in this study was also strongly associated with several traditional renal and cardiovascular risk factors such as higher systolic blood pressure, insulin resistance, and glycosuria [32,33]. The importance of these renal and cardiovascular risk factors as determinants of albumin excretion rate in HIV-infected individuals may mark a shift in the significance of microalbuminuria in the current era of HIV in the USA. Rather than a marker of the severity of HIV infection and HIV-related renal disease, the increased prevalence of microalbuminuria among HIV infected patients may signal an increase in their cardiovascular risk.

Our findings indicate that within the HIV-infected population, non-HIV factors may be more important predictors of microalbuminuria than HIV severity in the current era of HIV in the USA. In particular, the cardiovascular risk factors of increased systolic blood pressure, insulin resistance, and older age (risk factors previously noted in the general population) were strongly associated with microalbuminuria in our HIV-infected cohort. These results suggest that microalbuminuria may be a sign of current endothelial dysfunction and microvascular disease rather than of advanced HIV infection in this cohort, and may thus portend substantial risk of future cardiovascular disease events. Possible contributing factors include early kidney disease such as HIV-associated nephropathy, a marker of end organ damage related to comorbidities of diabetes mellitus or hypertension, or more diffuse endothelial cells dysfunction. Nevertheless, after adjustment for non-HIV factors, HIV itself is a major risk factor.

A relationship between microalbuminuria and current use of NNRTI was noted but was not as strong as the association of microalbuminuria with other measures, such as HOMA and CD4 lymphocyte count. While the potential for an indication bias related to the prescription of a class of antiretroviral medications such as NNRTI is not intuitive, it does remain a 
possibility. However, clearly, the limited strength of the relationship in the setting of multiple hypothesis-testing with dozens of individual and classes of medications should be reflected in its interpretation. While certain antiretroviral medications have been associated with acute renal failure and nephrolithiasis [34-37], glomerular damage has not previously been reported with those medications and they were not apparently associated with microalbuminuria in this study. Tenofovir use was very low at the time of study; indinavir use was not associated with microalbuminuria.

Given the recent findings that even a very low ACR is a predictor of cardiovascular disease and death [38], a similar correlation of these findings with outcomes in HIV-infected persons as well as assessments of therapeutic interventions will be essential. Given the analogous clinical scenario of a decrement in microalbuminuria with agents that disrupt the renin-angiotensin axis among patients with diabetes mellitus [38], a similar therapeutic use among HIV-infected persons with microalbuminuria is plausible.

While the strengths of this study include recruitment of subjects from 16 geographically diverse centers, with subject demographics similar to those of HIV infected subjects in the USA [21], this study does have important limitations. With respect to study design, it is important to note that cross-sectional studies such as this may be affected by a survival bias. Additionally, causation and whether treatment of predictors such as systolic blood pressure and insulin resistance would decrease albuminuria in HIV cannot be determined from these data.

In summary, the presence of HIV infection was independently associated with a fivefold risk of micro-albuminuria as compared with an age-matched cohort without HIV infection. Cardiovascular risk factors appeared to be stronger predictors of microalbuminuria than markers of HIV severity. Persons with HIV infection and microalbuminuria therefore appear to potentially bear the burden of two separate pathologic processes: microvascular end organ damage related to known vascular risk factors, and HIV specific processes such as the direct viral infection of kidney cells [39]. The high prevalence of microalbuminuria among the HIV infected could be a harbinger of future increased risks of both kidney and cardiovascular disease. Further study defining the prognostic significance of microalbuminuria among HIV-infected persons will be essential.

\section{Acknowledgments}

FRAM is supported by grants from the National Institutes of Health (R01-DK-57508, R01-HL-74814, and R01HL-53359). NIH support for this project is also provided through grants to General Clinical Research Centers (M01-RR00036, M01-RR00051, M01-RR00052, M01-RR00054, M01-RR00083, M01-RR00636, and M01RR00865). Dr. Szczech's work is supported by grant DK02724-01A1 from the National Institutes of Health. Drs. van der Horst and Wohl are supported by the UNC Center for AIDS Research (P30-AI50410), the UNC AIDS Clinical Trials Unit (AI25868). Dr. Shlipak is supported by R01 HL073208-01, R01 DK066488-01, the American Federation for Aging Research and National Institute on Aging (Paul Beeson Scholars Program) and the Robert Wood Johnson Foundation (Generalist Faculty Scholars Program).

\section{References}

1. Szczech LA, Gange SJ, van der Horst C, Bartlett JA, Young M, Cohen MH, et al. Predictors of proteinuria and renal failure among women with HIV infection. Kidney Int. 2002; 61:195-202. [PubMed: 11786101]

2. Szczech LA, Hoover DR, Feldman JG, Cohen MH, Gange SJ, Gooze L, et al. The association between renal disease and outcomes among HIV-infected women taking and not taking antiretroviral therapy. Clin Infect Dis. 2004; 39:1199-1206. [PubMed: 15486845] 
3. Gardner LI, Klein RS, Szczech LA, Phelps RM, Tashima K, Rompalo AM, et al. Rates and risk factors for overall and specific condition-associated hospitalizations in HIV-infected women. J Acquir Immune Defic Syndr. 2003; 34:320-330. [PubMed: 14600579]

4. Gardner LI, Holmberg SD, Williamson JM, Szczech LA, Carpenter CC, Rompalo AM, et al. Development of proteinuria or elevated serum creatinine and mortality in HIV-infected women. J Acquir Immune Defic Syndr. 2003; 32:203-209. [PubMed: 12571531]

5. Kabanda A, Vandercam B, Bernard A, Lauwerys R, van Ypersele de Strihou C. Low molecular weight proteinuria in human immunodeficiency virus-infected patients. Am J Kidney Dis. 1996; 27:803-808. [PubMed: 8651244]

6. Kimmel PL, Umana WO, et al. Abnormal urinary protein excretion in HIV-infected patients. Clin Nephrol. 1993; 39:17-21. [PubMed: 8428402]

7. Luke DR, Sarnoski TP, Dennis S. Incidence of microalbuminuria in ambulatory patients with acquired immunodeficiency syndrome. Clin Nephrol. 1992; 38:69-74. [PubMed: 1516282]

8. Palella FJ Jr, Delaney KM, Moorman AC, Loveless MO, Fuhrer J, Satten GA, et al. The HIV Outpatient Study Investigators. Declining morbidity and mortality among patients with advanced human immunodeficiency virus infection. N Engl J Med. 1998; 338:853-860. [PubMed: 9516219]

9. Mocroft A, Ledergerber B, Katlama C, Kirk O, Reiss P, d'Arminio Monforte A, et al. Decline in the AIDS and death rates in the EuroSIDA study: an observational study. Lancet. 2003; 362:22-29. [PubMed: 12853195]

10. Carr A, Samaras K, Burton S, Law M, Freund J, Chisholm DJ, et al. A syndrome of peripheral lipodystrophy, hyperlipidaemia and insulin resistance in patients receiving HIV protease inhibitors. AIDS. 1998; 12:F51-F58. [PubMed: 9619798]

11. Safrin S, Grunfeld C. Fat distribution and metabolic changes in patients with HIV infection. AIDS. 1999; 13:2493-2505. [PubMed: 10630518]

12. Clotet B, van der Valk M, Negredo E, Reiss P. Impact of nevirapine on lipid metabolism. J Acquir Immune Defic Syndr. 2003; 34(Suppl 1):S79-S84. [PubMed: 14562862]

13. Bozzette SA, Ake CF, Tam HK, Chang SW, Louis TA. Cardiovascular and cerebrovascular events in patients treated for human immunodeficiency virus infection. N Engl J Med. 2003; 348:702_710. [PubMed: 12594314]

14. The Data Collection on Adverse Events of Anti-HIV Drugs (DAD) Study Group. Combination antiretroviral therapy and the risk of myocardial infarction. N Engl J Med. 2003; 349:1993-2003. [PubMed: 14627784]

15. Hillege HL, Fidler V, Diercks GF, van Gilst WH, de Zeeuw D, van Veldhuisen DJ, et al. Urinary albumin excretion predicts cardiovascular and noncardiovascular mortality in general population. Circulation. 2002; 106(14):1777-1782. [PubMed: 12356629]

16. James MA, Fotherby MD, Potter JF. Screening tests for microalbuminuria in non-diabetic elderly subjects and their relation to blood pressure. Clin Sci. 1995; 88:185-190. [PubMed: 7720343]

17. Mattock MB, Morrish NJ, Viberti G, Keen H, Fitzgerald AP, Jackson G, et al. Prospective Study of microalbuminuria as predictor of mortality in NIDDM. Diabetes. 1992; 41:736-741. [PubMed: 1587400]

18. Roest M, Banga JD, Janssen WM, Grobbee DE, Sixma JJ, de Jong PE, et al. Excessive urinary albumin levels are associated with future cardiovascular mortality in postmenopausal women. Circulation. 2001; 103:3057-3061. [PubMed: 11425768]

19. Chen J, Muntner P, Hamm LL, Jones DW, Batuman V, Fonseca V, et al. The metabolic syndrome and chronic kidney disease in U.S. adults. Ann Intern Med. 2004; 140:167-174. [PubMed: 14757614]

20. Kurella M, Lo JC, Chertow GM. Metabolic syndrome and the risk for chronic kidney disease among nondiabetic adults. J Am Soc Nephrol. 2005; 16:2134-2140. [PubMed: 15901764]

21. Tien PC, Benson C, Zolopa AR, Sidney S, Osmond D, Grunfeld C, The FRAM Study Investigators. The study of fat redistribution and metabolic change in HIV infection (FRAM): methods, design, and sample characteristics. Am J Epidemiol. 2006; 163:860-869. [PubMed: 16524955] 
22. Friedman GD, Cutter GR, Donahue RP, Hughes GH, Hulley SB, Jacobs DR Jr, et al. CARDIA: study design, recruitment, and some characteristics of the examined subjects. J Clin Epidemiol. 1988; 41:1105-1116. [PubMed: 3204420]

23. Study of Fat Redistribution and Metabolic Change in HIV Infection. Fat distribution in men with HIV infection. J Acquir Immune Defic Syndr. 2005; 40:121-131. [PubMed: 16186728]

24. Nakamura Y, Myers BD. Charge selectivity of proteinuria in diabetic glomerulopathy. Diabetes. 1988; 37:1202. [PubMed: 3410164]

25. Nathan DM, Rosenbaum C, Protasowicki VD. Single-void samples can be used to estimate quantitative proteinuria. Diabetes Care. 1987; 10:414. [PubMed: 3622198]

26. Zelmanovitz T, Gross JL, Oliveira JR, Paggi A, Tatsch M, Azevedo MJ. The receiver operating characteristics curve in the evaluation of a random urine specimen as a screening test for diabetic nephropathy. Diabetes Care. 1997; 20:516. [PubMed: 9096972]

27. Eknoyan G, Hostetter T, Bakris GL, Hebert L, Levey AS, Parving HH, et al. Proteinuria and other markers of chronic kidney disease: A position statement of the national kidney foundation (NKF) and the National Institute of Diabetes and Digestive and Kidney Diseases (NIDDK). Am J Kidney Dis. 2003; 42:617. [PubMed: 14520612]

28. Jacobs DR Jr, Murtaugh MA, Steffes M, Yu X, Roseman J, Goetz FC. Gender- and race-specific determination of albumin excretion rate using albumin-to-creatinine ration in single, untimed urine specimens. Am J Epidemiol. 2002; 155:1114-1119. [PubMed: 12048225]

29. Cockcroft DW, Gault MH. Prediction of creatinine clearance from serum creatinine. Nephron. 1976; 16:31-41. [PubMed: 1244564]

30. Wallace TM, Ley JC, Matthews DR. Use and abuse of HOMA modeling. Diabetes Care. 2004; 27:1487-1495. [PubMed: 15161807]

31. Efron, B.; Tibshirani, R. An Introduction to the Bootstrap. Chapman and Hall; London: 1993.

32. Cirillo M, Senigalliesi L, Laurenzi M, et al. Microalbuminuria in nondiabetic adults: relation of blood pressure, body mass index, plasma cholesterol levels, and smoking: The Gubbio Population Study. Arch Intern Med. 1998; 158:1933-1939. [PubMed: 9759691]

33. Murtaugh MA, Jacobs DR Jr, Yu X, Gross MD, Steffes M, Coronary Artery Risk Development in Young Adults Study. Correlates of urinary albumin excretion in young adult blacks and whites: the Coronary Artery Risk Development in Young Adults Study. Am J Epidemiol. 2003; 158:676686. [PubMed: 14507604]

34. Berns JS, Cohen RM, Silverman M, Turner J. Acute renal failure due to indinavir crystalluria and nephrolithiasis: report of two cases. Am J Kidney Dis. 1997; 30:558-560. [PubMed: 9328372]

35. Daudon M, Estepa L, Viard JP, Joly D, Jungers P. Urinary stones in HIV-1 positive patients treated with indinavir. Lancet. 1997; 349:1294-1205. [PubMed: 9142068]

36. Karras A, Lafaurie M, Furco A, Bourgarit A, Droz D, Sereni D, et al. Tenofovir-related nephrotoxicity in human immunodeficiency virus-infected patients: three cases of renal failure, Fanconi syndrome, and nephrogenic diabetes insipidus. Clin Infect Dis. 2003; 36:1070-1073. [PubMed: 12684922]

37. Creput C, Gonzalez-Canali G, Hill G, Piketty C, Kazatchkine M, Nochy D. Renal lesions in HIV-1-positive patient treated with tenofovir. AIDS. 2003; 17:935-937. [PubMed: 12660548]

38. Parving HH, Lehnert H, Brochner-Mortensen J, Gomis R, Andersen S, Arner P, et al. The effect of irbesartan in patients with type 2 diabetes and microalbuminuria study group. the effect of irbesartan on the development of diabetic nephropathy in patients with type 2 diabetes. $\mathrm{N}$ Engl $\mathrm{J}$ Med. 2001; 345:870-878. [PubMed: 11565519]

39. Bruggeman LA, Dikman S, Meng C, Quaggin SE, Coffman TM, Klotman PE. Nephropathy in human immunodeficiency virus-1 transgenic mice is due to renal transgene expression. J Clin Invest. 1997; 100:84-92. [PubMed: 9202060] 


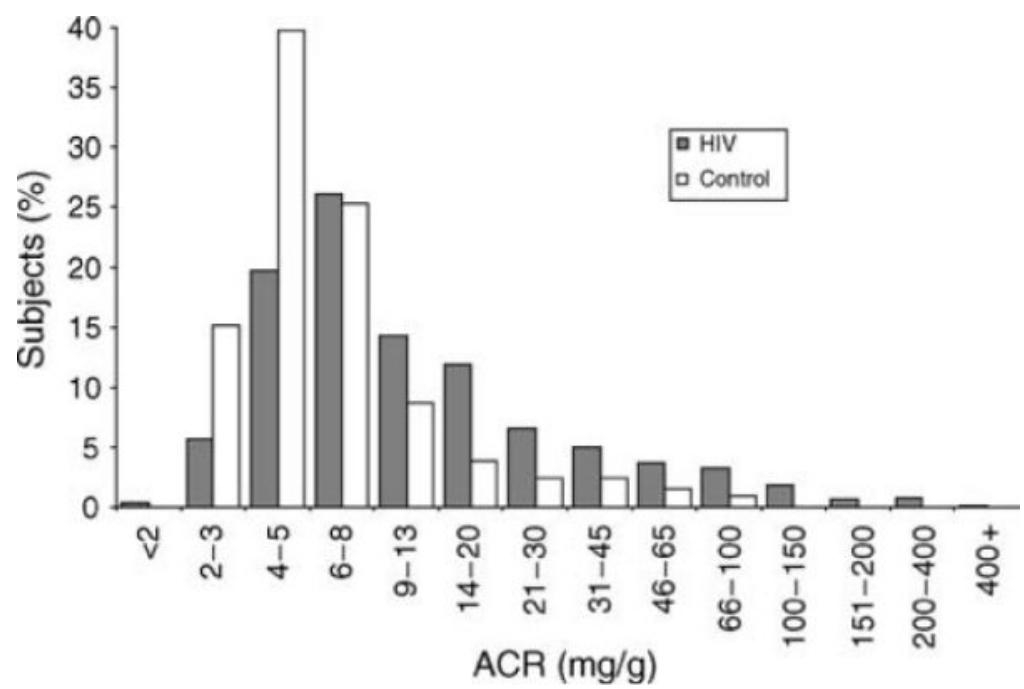

Fig. 1.

Distribution of ACR among HIV-infected and control participants. 


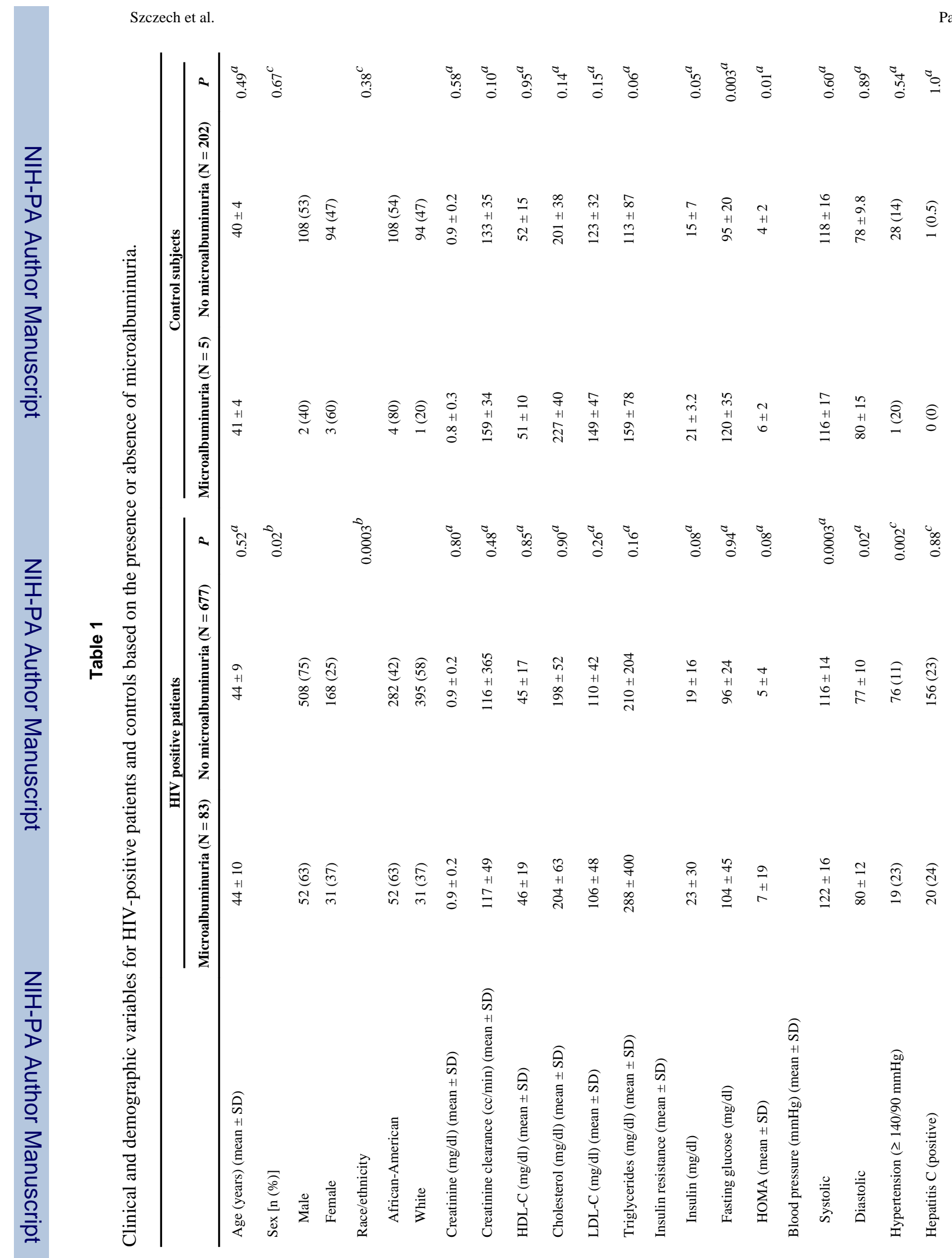

AIDS. Author manuscript; available in PMC 2011 October 9. 


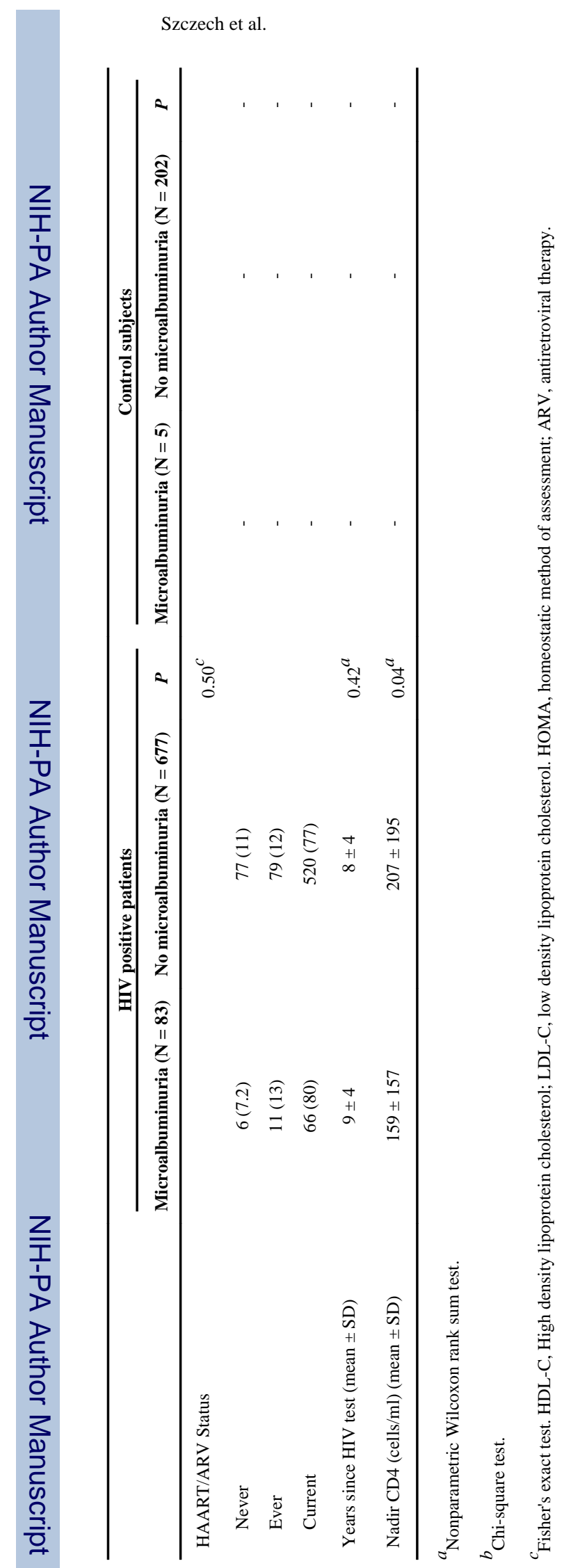

AIDS. Author manuscript; available in PMC 2011 October 9. 
Table 2

Microalbuminuria among HIV-infected patients and control subjects [urinary albumin/creatinine ratio (ACR) $>30 \mathrm{mg} / \mathrm{gm}]$.

\begin{tabular}{lccc}
\hline & HIV positive patients $(\mathbf{n}=\mathbf{7 6 0})$ & Control subjects $(\mathbf{n}=\mathbf{2 0 7})$ & $\boldsymbol{P}$ \\
\hline Median ACR $^{a}$ & $5(\mathrm{IQR}, 8.5)$ & $4(\mathrm{IQR}, 2.0)$ & \\
With microalbuminuria [n (\%)] & $83(10.9)$ & $5(2.4)$ & $<0.0001^{b}$ \\
Unadjusted OR & $4.95(95 \% \mathrm{CI}, 1.98-12.38)$ & 0.0008 \\
Adjusted $\mathrm{OR}^{c}$ & $5.11(95 \% \mathrm{CI}, 1.97-13.31)$ & \\
\hline
\end{tabular}

${ }^{a}$ Continuous form of ACR.

${ }^{b}$ Chi-square test.

${ }^{c}$ Adjusted for race, serum triglyceride measurement, human insulin and systolic blood pressure, via logistic regression. IQR, Interquartile range; $\mathrm{OR}$, odds ratio; $\mathrm{CI}$, confidence interval. 
Table 3

Results of multivariate model assessing association of HIV-related and non-HIV-related factors with urine ACR in HIV-infected subjects.

\begin{tabular}{|c|c|c|}
\hline Variable & Effect $[\%(95 \% \mathrm{CI})]$ & $P$ \\
\hline Age (per decade increase) & $10.5(1.7$ to 20.4$)$ & 0.02 \\
\hline \multicolumn{3}{|l|}{ Sex } \\
\hline Female versus male & $-14.8(-28.0$ to 3.3$)$ & 0.10 \\
\hline \multicolumn{3}{|l|}{ Race } \\
\hline African-American versus Caucasian & $33.0(13.0$ to 54.7$)$ & 0.001 \\
\hline HOMA > 4 & $32.4(15.2$ to 53.3$)$ & $<0.0001$ \\
\hline \multicolumn{3}{|l|}{ Systolic blood pressure } \\
\hline $120-140$ versus $<120 \mathrm{mmHg}$ & $20.6(3.5$ to 40.5$)$ & 0.010 \\
\hline$>140$ versus $<120 \mathrm{mmHg}$ & $43.2(-0.9$ to 108.4$)$ & 0.06 \\
\hline Family history of hypertension & $16.6(1.5$ to 33.0$)$ & 0.03 \\
\hline Urine glucose (present versus absent) & $113.2(33.9$ to 222.2$)$ & 0.002 \\
\hline \multicolumn{3}{|l|}{ Current CD4 lymphocyte count } \\
\hline $200-400$ versus $<200$ cells $/ \mathrm{ml}$ & $-23.8(-39.2$ to -5.2$)$ & 0.009 \\
\hline$>400$ versus $<200$ cells $/ \mathrm{ml}$ & $-25.7(-40.3$ to -8.3$)$ & 0.005 \\
\hline Current HIV RNA level (per 10-fold increase) & $8.7(0.1$ to 19.0$)$ & 0.05 \\
\hline Current use of NNRTI & $21.9(4.5$ to 41.6$)$ & 0.01 \\
\hline
\end{tabular}

HOMA, homeostatic method of assessment; NNRTI, non-nucleoside reverse transcriptase inhibitor. 